\title{
Production of lactic and acetic acids during fermentation of milk fortified with kiwi juice using Saccharomyces boulardii and lactobacilli
}

\author{
Ahmed Hassan Mousa ${ }^{1-3}$, Gang Wang ${ }^{2-4,6}$, Hao Zhang $^{2-5,6 *}$ \\ ${ }^{1}$ Faculty of Environmental Agricultural Science, Arish University, El Arish 45526, Egypt, ${ }^{2}$ State Key Laboratory of Food Science \\ and Technology, ${ }^{3}$ School of Food Science and Technology, ${ }^{4}$ International Joint Research Center for Probiotics \& Gut Health, \\ ${ }^{5}$ National Engineering Research Center for Functional Food, Jiangnan University, Wuxi, Jiangsu 214122, 6(Yangzhou) Institute \\ of Food Biotechnology, Jiangnan University, Yangzhou 225004, China
}

*For correspondence: Email: zhanghao@jiangnan.edu.cn; Tel: 0086-13601517819

Sent for review: 20 December 2018

Revised accepted: 22 March 2019

\begin{abstract}
Purpose: To investigate the synergistic effect of Saccharomyces boulardii and lactobacilli on lactic and acetic acids produced during fermentation of milk fortified with kiwi juice, relative to fermentation of unfortified milk.

Methods: Skimmed milk was fortified with kiwi juice (4\% v/v) and fermented for $12 \mathrm{~h}$ at $37{ }^{\circ} \mathrm{C}$ by a combination of $\mathrm{S}$. boulardii and lactobacilli strains. Lactic and acetic acids were determined using gas chromatography-mass spectrometry (GS-MS).

Results: The presence of kiwi juice in the milk stimulated the production of lactic $(1.35 \mathrm{~g} / 100 \mathrm{~g})$ and acetic $(0.29 \mathrm{mg} / \mathrm{g})$ by $\mathrm{S}$. boulardii in the absence of lactobacilli. When S. boulardii was inoculated with $\mathrm{Lb}$. casei 20975 , the production of lactic acid and acetic acid increased to $2.36 \mathrm{~g} / 100 \mathrm{~g}$ and $0.71 \mathrm{mg} / \mathrm{g}$, respectively. Furthermore, acid production increased when Lb. plantarum RS (35-11), Lb. casei LCS, and Lb. plantarum JXJ (6 - 12) were inoculated into milk free of kiwi juice in which $S$. boulardii was grown. Saccharomyces boulardii resulted in marginal production of acids by Lb. fermentum F9.

Conclusion: These results show that acid production is positively affected by some lactobacilli strains in the milk whether fortified with kiwi juice or free of this juice. However, fermentation of these formulations for a period longer than $6 \mathrm{~h}$ may result in losses in acid yield.
\end{abstract}

Keywords: Fermented milk, Kiwi juice, Saccharomyces boulardii, Lactobacilli, Lactic acids, Acetic acid

This is an Open Access article that uses a fund-ing model which does not charge readers or their institutions for access and distributed under the terms of the Creative Commons Attribution License (http://creativecommons.org/licenses/by/4.0) and the Budapest Open Access Initiative (http://www.budapestopenaccessinitiative.org/read), which permit unrestricted use, distribution, and reproduction in any medium, provided the original work is properly credited.

Tropical Journal of Pharmaceutical Research is indexed by Science Citation Index (SciSearch), Scopus, International Pharmaceutical Abstract, Chemical Abstracts, Embase, Index Copernicus, EBSCO, African Index Medicus, JournalSeek, Journal Citation Reports/Science Edition, Directory of Open Access Journals (DOAJ), African Journal Online, Bioline International, Open-J-Gate and Pharmacy Abstracts

\section{INTRODUCTION}

Saccharomyces boulardii was first isolated from lychees fruit (Litchi chinensis) by a French microbiologist, Henri Boulard in Indochina where lychees grow and prefer warm tropical climate [1]. Saccharomyces boulardii is used in many fermented dairy products e.g. acidophilus milk [2]. Fermented dairy products are good vehicles for Lactobacillus strains since these cultures remain metabolically efficient [3]. Lactobacillus constitutes the largest genus of LAB: over 125 species and sub-species have been identified and recognized. A major characteristic of $L A B$ is 
the capacity to generate lactic acid and acetic acid as the principal or only fermentation products [4].

Lactobacillus species (e.g. casei, plantarum and fermentum) are considered ubiquitous bacteria that can be used largely as culture or in mixtures in traditional dairy products. Therefore, the production of fermented dairy products inoculated with Lactobacillus strains has been developed in the last decade $[3,5,6]$. Fortification of milk with fruit juices (e.g., kiwi) has been reported to increase the bioavailability of nutrients [7]. Furthermore, lactobacilli are able to ferment fruit juices such as kiwi spontaneously, which reveals their reliability and consistency of performance.

Although yeasts have been considered as an integral part of the microflora of many dairyrelated products, the active use of yeasts as dietary adjuncts for lactobacilli has been limited. However, Kefir is an exception since it is a fermented milk-based beverage manufactured using yeasts and bacteria [5]. In addition, $S$. boulardii could grow to a great extent in combination with the starter culture bacteria after inoculation in a dairy product such as yogurt [8]. Therefore, the synergistic effects of $S$. boulardii and lactobacilli on dairy products have been reported [9]. It has been also reported that one of these synergistic effects is the optimal growth temperature of $37^{\circ} \mathrm{C}$ since it is about the same whether in the presence of $S$. boulardii alone or in combination with lactobacilli [10].

The combination of $S$. boulardii with lactobacilli by inoculation of the yeast into commercial milk products, has been demonstrated to enhance the metabolic activities of the microorganisms [6]. Although some studies have reported that $S$. boulardii may not be capable of lactose fermentation [11], it has been shown that the metabolism of lactobacilli during fermentation of dairy products is stimulated by the fermentative functions of $S$. boulardii $[6,8]$.

The organic acids produced by lactobacilli are known to affect Saccharomyces metabolism if they are inoculated together [12]. Nevertheless, the organic acids are not always produced by lactobacilli alone because the yeast also generates the same acids as minor products of metabolism [10].

The main purpose of this study was to determine the rates of lactic and acetic acids production by $S$. boulardii alone or in combination with lactobacilli during fermentation of milk fortified with kiwi juice or free of this juice.

\section{EXPERIMENTAL}

\section{Materials}

Skimmed milk powder was purchased from Guang Ming Co. Ltd (Wenzhou, China). Kiwi (Actinidia chinensis) was purchased from a local retail market in China, while MF-Millipore membrane filter (mixed cellulose esters, asbestos monitoring, $0.22 \mu \mathrm{m}, 25 \mathrm{~mm}$, white, gridded) was purchased from Sigma-Aldrich (Shanghai, China). All chemicals used in the experiments were of analytical grade and of high purity.

\section{Microorganisms and media}

Saccharomyces boulardii (Reflor; Biocodex, Cedex, France), and all of the Lactobacillus strains used in this study were obtained from the Synergistic Innovation Center for Food Safety and Nutrition, Jiangnan Uni. (Wuxi, China). Yeast extract peptone dextrose (YPD) was used to activate $S$. boulardii, while DeMan, Rogosa, Sharpe (MRS) was used to activate lactobacilli.

\section{Preparation of the media substrates and fermentation}

Skimmed milk powder was reconstituted at a concentration of $11 \%(\mathrm{w} / \mathrm{v})$, pasteurized for 15 sec at $72{ }^{\circ} \mathrm{C}$, and then sterilized using MFMillipore membrane filter $(0.22 \mu \mathrm{m} / 25 \mathrm{~mm})$. Kiwi Juice was extracted using Santos blender and sterilized using MF-Millipore membrane filter $(0.22 \mu \mathrm{m} / 25 \mathrm{~mm})$. The milk was fortified with kiwi juice to a level of $4 \%(\mathrm{v} / \mathrm{v})$. The formulations of skimmed milk fortified with kiwi juice, and skimmed milk free of this juice were distributed in $150 \mathrm{~mL}$ quantities into sterile Erlenmeyer flasks $(250 \mathrm{~mL})$. They were then inoculated with an active culture of $S$. boulardii, alone or together with S. boulardii and active culture of lactobacilli strains. The inoculated substrates were allowed to ferment for $12 \mathrm{~h}$ at $37{ }^{\circ} \mathrm{C}$ under anaerobic conditions. Samples were withdrawn at regular intervals for analysis.

\section{Gas chromatography-mass spectrometry}

Derivatization of analyte for GC-MS was performed according to a previous protocol [13] with few modifications. Lactic and acetic acids were determined with Thermo/GC-MS/Trace 1310 (TSQ 8000 Evo, Switzerland) using a column of the Rtx-5MS capillary (dimensions: 30 $\mathrm{m}, 0.25 \mathrm{~mm} / 0.25 \mu \mathrm{m}$ ). The carrier gas was helium at a flow rate of $35.0 \mathrm{~cm}^{3} / \mathrm{sec}$. The initial temperature was $320^{\circ} \mathrm{C}\left(90^{\circ} \mathrm{C} / \mathrm{min}\right)$, and was held for $5 \mathrm{~min}$. 


\section{Statistical analysis}

Data are expressed as mean \pm standard deviation (SD) of seven treatments (triplicate samples) using SPSS 19.0 software. Significant differences between treatment groups were determined using Duncan's multiple ranges. Values of $p<0.05$ were assumed significant.

\section{RESULTS}

The natural amounts of lactic acid and acetic acid detected in all of the treatments prior to fermentation were $0.098-0.102 \mathrm{~g} / 100 \mathrm{~g}$ and $0.085-0.086 \mathrm{mg} / \mathrm{g}$, respectively (Tables $1 \& 2$ ). For milk fortified with kiwi juice, $S$. boulardii and the facultative hetero-fermentative $L b$. casei 20975 together significantly increased yields of lactic acid and acetic acid to maximum values of $2.36 \mathrm{~g} / 100 \mathrm{~g}$ and $0.71 \mathrm{mg} / \mathrm{g}$, respectively. When kiwi juice-free milk was inoculated with $S$. boulardii and 20975 together, the production of acids still occurred and was higher when compared with other treatments, but was reduced to $2.02 \mathrm{~g} / 100 \mathrm{~g}$ for lactic, and $0.63 \mathrm{mg} / \mathrm{g}$ for acetic acid. Remarkably, the amount of acids produced increased in milk free of added kiwi juice, when compared with kiwi-fortified milk where $S$. boulardii was inoculated with the facultative hetero-fermentative $L b$. casei LCS, Lb. plantarum RS (35 - 11) or even Lb. plantarum JXJ (6 - 12).

These facultative hetero-fermentative strains increased lactic acid production within $6 \mathrm{~h}$ $(1.751 .81 \mathrm{~g} / 100 \mathrm{~g})$ and differed significantly $(p<$ $0.05)$, when compared with the other treatments. The amount of acetic acid produced increased to $\leq 0.56 \mathrm{mg} / \mathrm{g}$ with $S$. boulardii when inoculated with RS (35-11) or JXJ (6-12), but was greater than $0.23 \mathrm{mg} / \mathrm{g}$ observed for LCS. On the other hand, the presence of kiwi juice in milk resulted in increased acid production $(1.35 \mathrm{~g} / 100 \mathrm{~g}$ for lactic, and $0.29 \mathrm{mg} / \mathrm{g}$ for acetic) when $S$. boulardii was inoculated alone. However, the increase was not significant $(p>0.05)$, when compared with the case where Lb. plantarum RS (35-11) was present. In milk with or without added kiwi juice, acid production was as low as $\leq 1.21$ $\mathrm{g} / 100 \mathrm{~g}$ (for lactic) and $\leq 0.16 \mathrm{mg} / \mathrm{g}$ (for acetic acid) when $S$. boulardii was cultured together with the obligate hetero-fermentative $L b$. fermentum F9. The obligate hetero-fermentative Lb. fermentum F16 was more compatible with $S$. boulardii than with F9 when it was inoculated together into kiwi-based milk, resulting in increased production of acids to a maximum of $1.71 \mathrm{~g} / 100 \mathrm{~g}$ ( for lactic acid), and $0.26 \mathrm{mg} / \mathrm{g}$ (for acetic acid). However, these did not differ significantly, when compared with RS (35 - 11) $(p>0.05)$.

\section{DISCUSSION}

Lactic and acetic acids are mainly produced by microorganisms through breakdown of milk lactose [14]. In milk fortified with kiwi juice or milk free of this juice, inoculation with $S$. boulardii and lactobacilli increased the acid production rapidly and to a higher degree, relative to when $S$. boulardii was used alone. However, the acid production declined early after reaching maximum levels within $6 \mathrm{~h}$. This was to be expected since the competition from the $S$. boulardii caused a stress on lactobacilli metabolism.

Moreover, acid production by $S$. boulardii in milk free of added kiwi juice (control) seemed to be triggered by the unavailability of fermentable sugars, and it may be indicative of the doubtful capability of $S$. boulardii to ferment lactose and produce acids [15]. This was to be expected since $S$. boulardii produced acids marginally when it was allowed to grow in the absence of lactobacilli. However, the production of acids by $S$. boulardii alone increased when the milk was fortified with kiwi juice, indicating availability of fermentable sugars for yeast metabolism. Therefore, the increased acid production was associated with presence of $S$. boulardii alone, indicating the acidic environment caused by the presence of kiwi juice.

However, it must be pointed out that the relatively increased production of acids in the presence of the lactobacilli might have been employed by $S$. boulardii as a carbon source. After reaching maximum levels, the production of acids declined as rapidly as when lactobacilli was present, indicating predictable uptake of the acids by $S$. boulardii. Therefore, lactobacilli could be much more compatible with $S$. boulardii in milk free of kiwi juice, or even kiwi-based milk.

As expected, the acidity of kiwi juice induced microbial consumption of the fermentable sugars, and resulted in increased acid production during fermentation by yeast and lactobacilli. On the other hand, it has been suggested that the high acidity of yeast vehicle might pose a potent inhibition to the viability of Saccharomyces [16]. However, this is not consistent with the results of the present study. The enhanced production of acids by $L b$. casei as reported here may be related to the vitamins contained in the kiwi juice. 
Table 1: Changes in lactic acid content $(\mathrm{g} / 100 \mathrm{~g})$ during fermentation at $37^{\circ} \mathrm{C}$ for $12 \mathrm{~h}$ by Saccharomyces boulardii, or by a combination of $\mathrm{S}$. boulardii and lactobacilli strains

\begin{tabular}{|c|c|c|c|c|c|c|c|}
\hline \multirow[b]{2}{*}{ Period (h) } & \multicolumn{7}{|c|}{$\begin{array}{l}\text { Treatments* } \\
\text { Media substrate: milk alone (Control) }\end{array}$} \\
\hline & S. boulardii & S. boulardii+20975 & S. boulardii+LCS & S. boulardii+RS & S. boulardif+JXJ & S. boulardiit+F9 & S. boulardii+F16 \\
\hline 0 & $0.10 \pm 0.00^{a}$ & $0.10 \pm 0.00^{\mathrm{a}}$ & $0.10 \pm 0.00^{\mathrm{a}}$ & $0.10 \pm 0.00^{a}$ & $0.10 \pm 0.00^{\mathrm{a}}$ & $0.10 \pm 0.00^{\mathrm{a}}$ & $0.10 \pm 0.00^{\mathrm{a}}$ \\
\hline 2 & $0.12 \pm 0.02^{\mathrm{e}}$ & $1.76 \pm 0.02^{\mathrm{a}}$ & $1.71 \pm 0.08^{\mathrm{a}}$ & $1.76 \pm 0.04^{a}$ & $1.34 \pm 0.02^{c}$ & $0.76 \pm 0.01^{\mathrm{d}}$ & $1.49 \pm 0.03^{b}$ \\
\hline 4 & $0.13 \pm 0.01^{\mathrm{e}}$ & $1.94 \pm 0.04^{a}$ & $1.74 \pm 0.09^{b}$ & $1.78 \pm 0.02^{\mathrm{b}}$ & $1.75 \pm 0.01^{\mathrm{b}}$ & $1.10 \pm 0.03^{d}$ & $1.57 \pm 0.05^{\mathrm{c}}$ \\
\hline 6 & $0.14 \pm 0.01^{\mathrm{e}}$ & $2.02 \pm 0.01^{a}$ & $1.75 \pm 0.04^{b}$ & $1.81 \pm 0.04^{\mathrm{b}}$ & $1.79 \pm 0.03^{b}$ & $1.12 \pm 0.03^{\mathrm{d}}$ & $1.68 \pm 0.06^{c}$ \\
\hline 8 & $0.15 \pm 0.01^{e}$ & $1.88 \pm 0.04^{a}$ & $1.62 \pm 0.02^{c}$ & $1.78 \pm 0.01^{\mathrm{D}}$ & $1.76 \pm 0.01^{\mathrm{b}}$ & $1.11 \pm 0.04^{a}$ & $1.65 \pm 0.03^{c}$ \\
\hline 10 & $0.15 \pm 0.02^{g}$ & $1.81 \pm 0.02^{a}$ & $0.94 \pm 0.03^{\mathrm{e}}$ & $1.22 \pm 0.02^{a}$ & $1.62 \pm 0.05^{\mathrm{b}}$ & $0.32 \pm 0.05^{\dagger}$ & $1.30 \pm 0.06^{\mathrm{c}}$ \\
\hline \multirow[t]{2}{*}{12} & $0.12 \pm 0.01^{\dagger}$ & $0.94 \pm 0.03^{\mathrm{b}}$ & $0.22 \pm 0.04^{\mathrm{e}}$ & $0.34 \pm 0.04^{d}$ & $1.12 \pm 0.02^{\mathrm{a}}$ & $0.18 \pm 0.01^{\mathrm{e}}$ & $0.81 \pm 0.02^{\mathrm{C}}$ \\
\hline & \multicolumn{7}{|c|}{ Media substrate: kiwi juice-fortified milk (4\% v/v) } \\
\hline Period (h) & S. boulardii & S. boulardii+20975 & S. boulardii+LCS & S. boulardiit+RS & S. boulardii+JXJ & S. boulardiit+F9 & S. boulardiit+F16 \\
\hline 0 & $0.10 \pm 0.01^{a}$ & $0.10 \pm 0.01^{\mathrm{a}}$ & $0.10 \pm 0.01^{\mathrm{a}}$ & $0.10 \pm 0.01^{\mathrm{a}}$ & $0.10 \pm 0.01^{a}$ & $0.10 \pm 0.01^{\mathrm{a}}$ & $0.10 \pm 0.01^{\mathrm{a}}$ \\
\hline 2 & $0.52 \pm 0.04^{\mathrm{a}}$ & $1.52 \pm 0.02^{\mathrm{a}}$ & $1.20 \pm 0.01^{\mathrm{c}}$ & $1.28 \pm 0.04^{\mathrm{b}}$ & $1.32 \pm 0.05^{\mathrm{b}}$ & $0.34 \pm 0.03^{\mathrm{e}}$ & $1.28 \pm 0.01^{\mathrm{D}}$ \\
\hline 4 & $0.62 \pm 0.05^{\dagger}$ & $2.02 \pm 0.04^{a}$ & $1.54 \pm 0.03^{\mathrm{d}}$ & $1.69 \pm 0.02^{c}$ & $1.75 \pm 0.02^{b}$ & $0.95 \pm 0.04^{e}$ & $1.59 \pm 0.01^{\mathrm{d}}$ \\
\hline 6 & $1.09 \pm 0.02^{\mathrm{e}}$ & $2.36 \pm 0.04^{a}$ & $1.61 \pm 0.01^{c}$ & $1.73 \pm 0.02^{b}$ & $1.69 \pm 0.06^{\mathrm{b}}$ & $1.21 \pm 0.02^{d}$ & $1.71 \pm 0.05^{b}$ \\
\hline 8 & $1.33 \pm 0.02^{d}$ & $2.21 \pm 0.02^{a}$ & $1.36 \pm 0.04^{d}$ & $1.65 \pm 0.05^{b}$ & $1.53 \pm 0.01^{c}$ & $0.71 \pm 0.05^{\mathrm{e}}$ & $1.63 \pm 0.02^{b}$ \\
\hline 10 & $1.35 \pm 0.04^{\mathrm{D}}$ & $1.92 \pm 0.05^{\mathrm{a}}$ & $1.11 \pm 0.02^{\mathrm{a}}$ & $1.34 \pm 0.04^{\mathrm{D}}$ & $1.13 \pm 0.03^{a}$ & $0.27 \pm 0.02^{\mathrm{e}}$ & $1.27 \pm 0.01^{\mathrm{c}}$ \\
\hline 12 & $0.46 \pm 0.03^{c}$ & $1.64 \pm 0.05^{\mathrm{a}}$ & $0.22 \pm 0.01^{a}$ & $0.46 \pm 0.02^{c}$ & $0.40 \pm 0.04^{c}$ & $0.13 \pm 0.01^{e}$ & $0.61 \pm 0.06^{\mathrm{b}}$ \\
\hline
\end{tabular}

same row denote significant differences $(p<0.05)$ among treatments for the same fermentation period 
Table 2: Changes in acetic acid content (mg/g) during fermentation at $37{ }^{\circ} \mathrm{C}$ for $12 \mathrm{~h}$ by Saccharomyces boulardii, or by a combination of $S$. boulardii and lactobacilli strains

\begin{tabular}{|c|c|c|c|c|c|c|c|}
\hline \multirow[b]{2}{*}{$\begin{array}{l}\text { Period } \\
\text { (h) }\end{array}$} & \multicolumn{7}{|c|}{$\begin{array}{c}\text { Treatments }^{*} \\
\text { Media substrate: milk alone (Control) }\end{array}$} \\
\hline & $\begin{array}{l}\text { S. } \\
\text { boulardii }\end{array}$ & $\begin{array}{l}\text { S. } \\
\text { boulardii+20975 }\end{array}$ & $\begin{array}{l}\text { S. } \\
\text { boulardii+LCS }\end{array}$ & $\begin{array}{l}\text { S. } \\
\text { boulardii+RS }\end{array}$ & $\begin{array}{l}\text { S. } \\
\text { boulardii+JXJ }\end{array}$ & $\begin{array}{l}\text { S. } \\
\text { boulardii+F9 }\end{array}$ & $\begin{array}{l}\text { S. } \\
\text { boulardii+F16 }\end{array}$ \\
\hline 0 & $\begin{array}{l}0.09 \pm \\
0.00^{\mathrm{a}}\end{array}$ & $0.09 \pm 0.00^{a}$ & $0.09 \pm 0.00^{a}$ & $0.09 \pm 0.00^{a}$ & $0.09 \pm 0.00^{a}$ & $0.09 \pm 0.00^{a}$ & $0.09 \pm 0.00^{\mathrm{a}}$ \\
\hline 2 & $\begin{array}{l}0.09 \pm \\
0.00^{\mathrm{d}}\end{array}$ & $0.54 \pm 0.01^{a}$ & $0.14 \pm 0.03^{a}$ & $0.36 \pm 0.05^{\mathrm{c}}$ & $0.42 \pm 0.03^{\mathrm{b}}$ & $0.10 \pm 0.02^{a}$ & $0.12 \pm 0.04^{a}$ \\
\hline 4 & $\begin{array}{l}0.09 \pm \\
0.01^{\mathrm{d}}\end{array}$ & $0.61 \pm 0.02^{\mathrm{a}}$ & $0.14 \pm 0.02^{\mathrm{cd}}$ & $0.45 \pm 0.05^{b}$ & $0.48 \pm 0.05^{\mathrm{b}}$ & $0.10 \pm 0.03^{d}$ & $0.18 \pm 0.02^{c}$ \\
\hline 6 & $\begin{array}{l}0.09 \pm \\
0.01^{d}\end{array}$ & $0.63 \pm 0.04^{a}$ & $0.23 \pm 0.01^{c}$ & $0.54 \pm 0.01^{b}$ & $0.56 \pm 0.04^{b}$ & $0.10 \pm 0.04^{d}$ & $0.18 \pm 0.02^{c}$ \\
\hline 8 & $0.09 \pm$ & $0.61 \pm 0.01^{a}$ & $0.22 \pm 0.02^{a}$ & $0.42 \pm 0.03^{c}$ & $0.55 \pm 0.04^{\mathrm{D}}$ & $0.09 \pm 0.02^{\mathrm{e}}$ & $0.18 \pm 0.04^{a}$ \\
\hline 10 & $\begin{array}{l}0.04 \pm \\
0.00^{\mathrm{d}}\end{array}$ & $0.47 \pm 0.02^{\mathrm{a}}$ & $0.22 \pm 0.01^{c}$ & $0.32 \pm 0.01^{\mathrm{b}}$ & $0.47 \pm 0.03^{a}$ & $0.08 \pm 0.03^{d}$ & $0.05 \pm 0.01^{d}$ \\
\hline \multirow[t]{2}{*}{12} & $\begin{array}{l}0.04 \pm \\
0.00^{\mathrm{d}}\end{array}$ & $0.36 \pm 0.04^{a}$ & $0.08 \pm 0.02^{c}$ & $0.11 \pm 0.01^{c}$ & $0.26 \pm 0.01^{\mathrm{D}}$ & $0.03 \pm 0.01^{a}$ & $0.04 \pm 0.03^{a}$ \\
\hline & \multicolumn{7}{|c|}{ Media substrate: kiwi juice-fortified milk (4\% v/v) } \\
\hline $\begin{array}{l}\text { Period } \\
\text { (h) }\end{array}$ & $\begin{array}{l}\text { S. } \\
\text { boulardii }\end{array}$ & $\begin{array}{l}\text { S. } \\
\text { boulardii+20975 }\end{array}$ & $\begin{array}{l}\text { S. } \\
\text { boulardii+LCS }\end{array}$ & $\begin{array}{l}\text { S. } \\
\text { boulardii+RS }\end{array}$ & $\begin{array}{l}\text { S. } \\
\text { boulardii+JXJ }\end{array}$ & $\begin{array}{l}\text { S. } \\
\text { boulardii+F9 }\end{array}$ & $\begin{array}{l}\text { S. } \\
\text { boulardii+F16 }\end{array}$ \\
\hline 0 & $0.09 \pm$ & $0.09 \pm 0.00^{\mathrm{a}}$ & $0.09 \pm 0.00^{\mathrm{a}}$ & $0.09 \pm 0.00^{\mathrm{a}}$ & $0.09 \pm 0.00^{\mathrm{a}}$ & $0.09 \pm 0.00^{\mathrm{a}}$ & $0.09 \pm 0.00^{\mathrm{a}}$ \\
\hline 2 & $\begin{array}{l}0.12 \pm \\
0.01^{\mathrm{d}}\end{array}$ & $0.52 \pm 0.01^{\mathrm{a}}$ & $0.09 \pm 0.01^{a}$ & $0.11 \pm 0.04^{a}$ & $0.17 \pm 0.03^{\mathrm{D}}$ & $0.13 \pm 0.02^{\mathrm{cd}}$ & $0.16 \pm 0.02^{\mathrm{bc}}$ \\
\hline 4 & $\begin{array}{l}0.12 \pm \\
0.00^{d}\end{array}$ & $0.64 \pm 0.04^{a}$ & $0.15 \pm 0.01^{d}$ & $0.17 \pm 0.03^{d}$ & $0.31 \pm 0.01^{b}$ & $0.15 \pm 0.03^{d}$ & $0.25 \pm 0.04^{c}$ \\
\hline 6 & $\begin{array}{l}0.13^{ \pm} \\
0.00^{\mathrm{d}}\end{array}$ & $0.71 \pm 0.03^{\mathrm{a}}$ & $0.16 \pm 0.02^{a}$ & $0.22 \pm 0.03^{\mathrm{bc}}$ & $0.18 \pm 0.04^{\mathrm{ca}}$ & $0.16 \pm 0.02^{a}$ & $0.26 \pm 0.04^{\mathrm{D}}$ \\
\hline 8 & $\begin{array}{l}0.26 \pm \\
0.01^{\mathrm{b}}\end{array}$ & $0.66 \pm 0.03^{\mathrm{a}}$ & $0.13 \pm 0.01^{c}$ & $0.14 \pm 0.02^{\mathrm{c}}$ & $0.13 \pm 0.02^{C}$ & $0.13 \pm 0.05^{c}$ & $0.22 \pm 0.03^{b}$ \\
\hline 10 & $\begin{array}{l}0.29 \pm \\
0.00^{\mathrm{b}}\end{array}$ & $0.54 \pm 0.04^{\mathrm{a}}$ & $0.06 \pm 0.02^{\mathrm{d}}$ & $0.08 \pm 0.01^{d}$ & $0.07 \pm 0.02^{d}$ & $0.06 \pm 0.01^{d}$ & $0.16 \pm 0.02^{c}$ \\
\hline 12 & $\begin{array}{l}0.07 \pm \\
0.00^{\mathrm{b}}\end{array}$ & $0.25 \pm 0.03^{a}$ & $0.05 \pm 0.01^{\mathrm{Dc}}$ & $0.06 \pm 0.02^{\mathrm{bc}}$ & $0.05 \pm 0.01^{\mathrm{bc}}$ & $0.03 \pm 0.02^{c}$ & $0.07 \pm 0.01^{\mathrm{D}}$ \\
\hline
\end{tabular}

Data are expressed as mean \pm standard deviation (SD) of seven treatments (triplicate samples) which were analyzed in each treatment. Different superscript letters $\left({ }^{\mathrm{a}-\mathrm{g}}\right)$ in the same row denote significant differences $(p<$ 0.05 ) among treatments for the same fermentation period

An association has been suggested between high production of acids and the optimum fermentation temperature of $37{ }^{\circ} \mathrm{C}$ for the metabolic activity of $L b$. casei and $L b$. fermentum $[17,18]$. Kiwi minerals (e.g. magnesium) might also act as a prebiotic constituent, thus inducing acid production by lactobacilli.

In milk free of added kiwi juice, it was not clear whether the high production of acids was due to $S$. boulardii or metabolism of $L b$. plantarum [RS (35-11), JXJ (6-12)] and Lb. casei LCS, or both. It is known that $L b$. plantarum and $L b$. casei are facultative hetero-fermentative strains with capability to produce acids [19]. However, this does not rule out the possibility of acid production by $S$. boulardii [10], particularly since its level of acid production was substantial in the presence of kiwi juice. For this reason, few curds were aggregated in milk fortified with kiwi juice where Lb. plantarum [RS (35-11), JXJ (6-12)] and Lb. casei 20975 were present. The aggregation has been attributed to increased acid production caused by alterations in the electrostatic interactions in the protein network [20]. The solubility seen in the other treatments might due to low acid production.

\section{CONCLUSION}

This study addressed the stimulatory effect of fortification of milk with kiwi juice on acid production by yeast and some strains of lactobacilli. Although acid production was positively influenced by some of lactobacilli strains in the milk (whether fortified with kiwi juice or free of this juice), fermentation of these formulations for periods longer than $6 \mathrm{~h}$ may result in losses in acid yield. It is not obvious whether the negligible production of acetic acid was due to the slow speed of metabolism in some of the lactobacilli, or whether it was as a result of increased consumption of the acids by 
S. boulardii. Further investigations are required to ascertain the true situation.

\section{DECLARATIONS}

\section{Acknowledgement}

This work was supported by Priority Academic Program Development of Jiangsu Higher Education Institutions.

\section{Conflict of interest}

No conflict of interest is associated with this work

\section{Contribution of authors}

We declare that this work was done by the authors named in this article and all liabilities pertaining to claims relating to the content of this article will be borne by the authors. Hao Zhang conceived and designed the study. Gang Wang designed all the experiments and revised the manuscript. Ahmed Hassan Mousa performed the experiments, collected, analyzed the data, and wrote the manuscript.

\section{Open Access}

This is an Open Access article that uses a funding model which does not charge readers or their institutions for access and distributed under the terms of the Creative Commons Attribution License (http://creativecommons.org/licenses/by/ 4.0) and the Budapest Open Access Initiative (http://www.budapestopenaccessinitiative.org/rea d), which permit unrestricted use, distribution, and reproduction in any medium, provided the original work is properly credited.

\section{REFERENCES}

1. Prajapati $P$, Patel M, Krishnamurthy R. Saccharomyces boulardii-a probiotic of choice. CIBTech J Biotech 2013, 2(2): 1-6.

2. Kalpana D. Biotherapeutic properties of probiotic Saccharomyces species and its survival in acidophilus milk [dissertation]. [India]: National Dairy Research Institute; 2008.

3. Phillips M, Kailasapathy $K$, Tran L. Viability of commercial probiotic cultures (L. acidophilus, Bifidobacterium sp., $L$. casei, L. paracasei and L. rhamnosus) in cheddar cheese. Int J Food Microbiol 2006; 108(2): 276-280.

4. Wu R, Wang L, Wang J, Li H, Menghe B, Wu J, Guo M, Zhang $\mathrm{H}$. Isolation and preliminary probiotic selection of lactobacilli from koumiss in Inner Mongolia. J Basic Microbiol 2009; 49(3): 318-326.
5. SILVA CFG da, SANTOS FL, SANTANA LRR de, SILVA MVL, CONCEIÇÃO $T$ de A. Development and characterization of a soymilk Kefir-based functional beverage. Food Sci Technol 2018; 38(3): 543-550.

6. Lourens-Hattingh A, Viljoen BC. Growth and survival of a probiotic yeast in dairy products. Food Res Int 2001; 34(9): 791-796.

7. García-Nebot MJ, Alegría A, Barberá R, Clemente G, Romero F. Addition of milk or caseinophosphopeptides to fruit beverages to improve iron bioavailability? Food Chem 2010; 119(1): 141-148.

8. Niamah AK. Physicochemical and Microbial Characteristics of Yogurt with Added Saccharomyces Boulardii. Curr Res Nutr Food Sci J 2017; 5(3): 300307.

9. Gaon D, Garcia HU, Winter LU, Rodríguez NO, Quintas RI, Gonzalez SN, Oliver GU. Effect of Lactobacillus strains and Saccharomyces boulardii on persistent diarrhea in children. Med (Buenos Aires) 2003; 63(4): 293-298.

10. Thomas KC, Hynes SH, Ingledew WM. Effect of lactobacilli on yeast growth, viability and batch and semi-continuous alcoholic fermentation of corn mash. $J$ Appl Microbiol 2001; 90(5): 819-828.

11. Liu JJ, Kong II, Zhang GC, Jayakody LN, Kim H, Xia PF, Kwak S, Sung BH, Sohn JH, Walukiewicz HE, et al. Metabolic engineering of probiotic Saccharomyces boulardii. Appl Environ Microbiol 2016; 82(8): 22802287.

12. Edwards CG, Reynolds AG, Rodriguez A V, Semon MJ, Mills JM. Implication of acetic acid in the induction of slow/stuck grape juice fermentations and inhibition of yeast by Lactobacillus sp. Am J Enol Vitic 1999; 50(2): 204-210.

13. Zhao N, Zhang $C$, Yang Q, Guo Z, Yang B, Lu W, Li D, Tian F, Liu $X$, Zhang $H$, et al. Selection of taste markers related to lactic acid bacteria microflora metabolism for Chinese traditional paocai: a gas chromatography-mass spectrometry-based metabolomics approach. J Agric Food Chem 2016; 64(11): 2415-2422.

14. Ding WK, Shah NP. Survival of free and microencapsulated probiotic bacteria in orange and apple juices. Int Food Res J 2008; 15(2): 219-232.

15. Domingues L, Guimarães PMR, Oliveira C. Metabolic engineering of Saccharomyces cerevisiae for lactose/whey fermentation. Bioeng Bugs 2010; 1(3): 164-171.

16. Maiorella B, Blanch HW, Wilke CR. By-product inhibition effects on ethanolic fermentation by Saccharomyces cerevisiae. Biotechnol Bioeng 1983; 25(1): 103-121.

17. Mozzi F, de Giori GS, Oliver G, de Valdez GF. Exopolysaccharide production by Lactobacillus casei under controlled pH. Biotechnol Lett 1996; 18(4): 435439.

18. Zhang YU, Li S, Zhang C, Luo Y, Zhang $H$, Yang Z. Growth and exopolysaccharide production by Lactobacillus fermentum F6 in skim milk. African J Biotechnol 2011; 10(11): 2080-2091.

Trop J Pharm Res, April 2019; 18(4): 686 
Mousa et al

19. Kandler O. Carbohydrate metabolism in lactic acid bacteria. Antonie Van Leeuwenhoek 1983; 49(3): 209224.
20. Pinho O, Mendes E, Alves MM, Ferreira I. Chemical, physical, and sensorial characteristics of "Terrincho" ewe cheese: changes during ripening and intravarietal comparison. J Dairy Sci 2004; 87(2): 249-257. 